\title{
Pyrolysis Process Studies for Post Consumer Polyethene Waste Conversion and Upgrading of the Pyrolysis Oil
}

\author{
Jane Njoki Mburu' ${ }^{1}$ Paul Njogu Mwangi ${ }^{2}$, Jackson Wachira Muthengia ${ }^{3}$ \\ ${ }^{1}$ Institute of Energy and Environmental Technology, Jomo Kenyatta University of Agriculture and Technology, \\ P.O. Box 62000- 00200 Nairobi, Kenya \\ 2institute of Energy and Environmental Technology, Jomo Kenyatta University of Agriculture and Technology, \\ P.O. Box 62000- 00200 Nairobi, Kenya \\ ${ }^{3}$ Embu University College, School of Pure and Applied Sciences, P.O. 6-60100, EMBU KENYA
}

\begin{abstract}
There is a rising concern on the extensive environmental impacts resulting from unsustainable methods for management of post consumer waste plastics (PCPW) in Kenya. This study was conducted on conversion of PCPW into fuel gas and oils. Low Density Polythene (LDPE), High Density polythene (HDPE) and Polypropylene (PP) were heated in a locally assembled pyrolysis reactor at temperatures ranging between $200-500{ }^{\circ} \mathrm{C}$ and with heating rates of $5-15{ }^{\circ} \mathrm{C} /$ minute. Fractionation was conducted to refine the resultant crude oil into petrol at $150^{\circ} \mathrm{C}$ and diesel at $350{ }^{\circ} \mathrm{C}$. $359.64 \mathrm{~g} \pm 1.67,348.21 \mathrm{~g} \pm 0.97$ and $301.22 \mathrm{~g} \pm 1.5 \mathrm{of}$ crude oil for $500 \mathrm{~g}$ of HDPE, LDPE and PP resulted respectively. Diesel, petrol char and wax yields obtained were $(72 \% \pm 1.50,70 \% \pm 1.32,60 \% \pm 1.67)$ $(6 \% \pm 0.46,8.3 \% \pm 0.37,6 \% \pm 0.54),(1 \% \pm 0.67,5 \% \pm 1.21,2 \% \pm 0.57)$ and $(1 \% \pm 0.27,1.03 \% \pm 0.42,1 \% \pm 0.32)$ grams for HDPE, LDPE and $P P$ respectively. Mean values for petrol and diesel yields for HDPE and LDPE did not differ significantly with $\left(t_{\text {observed }}<t_{\text {calculated }}\right)$ for paired T-test (at $95 \%$ confidence level). Over $90 \% \pm 1.87$ conversion of plastic waste into fuel products was achieved. The plant was economically viable with an energy consumption of less than $5 \%$ of the total energy in $0.5 \mathrm{~kg}$ of waste plastics.
\end{abstract}

Keywords: Pyrolysis; Plastic, Waste, Energy.

\section{Introduction}

Plastic is a light, durable synthetic material that has found a lot of use in the modern world [1]. The plastic material comes in various types depending on its application. Polypropylene (PP) is the most widely used plastic type in the world today followed by Polyethylene (PE) [2].There are many other forms of other plastics whose applications depend on intended purpose.

Large production and use of plastics for various applications has resulted in huge volumes of plastic wastes [3]. This has lead to proliferation in the environment as a result of accumulation and fragmentation of plastic waste [4]. Most of this waste is non-degradable and highly resistant to light, acids and other tough conditions[5]. Some of the negative impacts resulting from poor waste plastic disposal include; choking and starving marine and wildlife, littering the surrounding environment and blocking drainage systems and water bodies [6]. Burning of plastics in open fires, landfills or by use of municipal solid wastes (MSW) incinerators releases toxic gas emissions. These gases include the persistent organic pollutants (POP's) such as dioxins and furans [7]. Studies have proved that this gases are carcinogenic and have endocrine disrupting effects in a wide range of biota [1]. Other emissions include the Green House Gases (GHG's) that cause global warming [8]-[9].

Plastic is derived from oil refining waste products that constitute petrochemicals produced from fossil oil and gas [10]. Plastics are therefore a potential source of energy when recycled to produce fuels [11]-[12]. Kenya suffers from Insufficient and high cost of energy that affects economic growth [13]-[14]. Plastic waste recycling for energy recovery is yet to be exploited in most of the developing countries where advanced Municipal Solid Waste (MSW) management technologies such as pyrolysis are yet to be fully implemented [15]. Recycling of post-consumer plastic waste for energy recovery through a cost effective and an environmentally friendly process could become an alternative means of obtaining cheap fuel [10] This calls for the development of a home grown pyrolysis process system and carrying out optimization studies of the process so as to make it economical and implementable.

\section{Methodology}

\subsection{Sample collection and preparation}

Plastic waste materials of LDPE, HDPE and PP were collected from the open dumpsites. Samples were washed with water and detergent. The cleaned samples were sundried and sorted out according to resin codes developed by the Society of Plastic Industries (SPI). The samples were sliced and pelletized into small pieces of dimensions of $2 \mathrm{~mm}$ and stored in polyethene bags.

\subsection{Pyrolytic Reactor design}

The pyrolysis process was conducted in a pyrolysis reactor made of mild steel and stainless steel. The reactor has a height of $20 \mathrm{~cm}$, an external diameter of $11 \mathrm{~cm}$ and an internal diameter of $8 \mathrm{~cm}$ and a $2 \mathrm{~kW}$ electric coil. The 


\section{International Journal of Science and Research (IJSR) \\ ISSN (Online): 2319-7064 \\ Index Copernicus Value (2013): 6.14 | Impact Factor (2014): 5.611}

reactor was capped with a ball valve to make it airtight and fitted with an outlet tube system at the top. The tubes had an outer diameter of $300 \mathrm{~mm}$ and an inner diameter of $200 \mathrm{~mm}$. The tubing system was passed through a condenser made of a $20 \mathrm{~L}$ container that was filled with cold water at room temperature. A pressure gauge of 1- 250 bars was connected to the top of the reactor. A thermocouple with digital temperature readout was connected to the reactor to control and monitor the internal reaction temperature during the pyrolysis process. High purity Nitrogen gas was purged into the reactor at a flow rate of $2 \mathrm{~L} / \mathrm{min}$ to maintain an oxygen free environment. The reactor was heated to a temperature range of 200 to $350{ }^{\circ} \mathrm{C}$ using a $2 \mathrm{kw}$ electric coil for a period of 1-2 hours. The pyrolysis batch reactor used for oil production in this study is as shown in Figure 1.

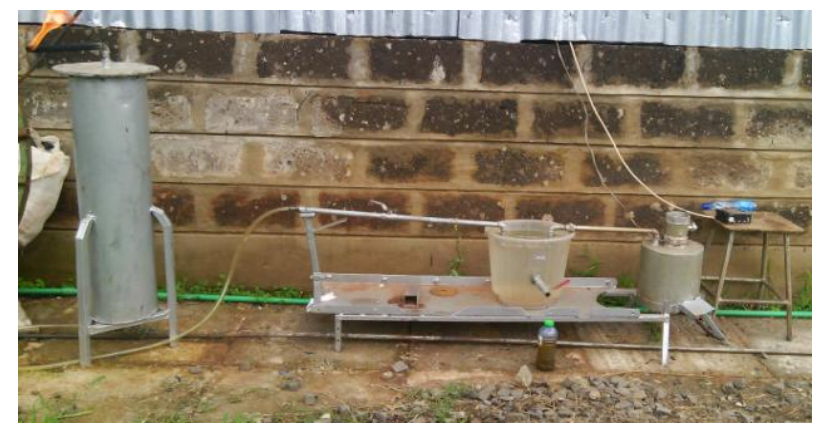

Figure 1: Pyrolysis batch reactor

\subsection{Pyrolytic conversion of HDPE, LDPE and PP waste plastics}

Batches of $500 \mathrm{~g}$ of pellets were introduced in the prewarmed reactor at $200{ }^{\circ} \mathrm{C}$. Nitrogen gas was purged into the reactor at a flow rate of $2 \mathrm{~L} / \mathrm{min}$. The sample was heated at temperatures ranging between $200-350{ }^{\circ} \mathrm{C}$ and with heating rate of $5{ }^{\circ} \mathrm{C}$ /minute. The non-condensable gases produced from the reactor were evacuated using the outlet tube system. The gases were passed through a condensation chamber that was operated at room temperature and the condensed oil stored in appropriate glass bottles and gases flared. The remaining solid residue was weighed for each batch and stored in pre-cleaned containers. Optimization studies were carried out by varying reactor temperature within the range of 200-350 ${ }^{\circ} \mathrm{C}, 350-450{ }^{\circ} \mathrm{C}$ and $450-500{ }^{\circ} \mathrm{C}$ respectively and at heating rates of 5,10 and $15^{\circ} \mathrm{C} /$ minute. Reaction times were also varied and catalysts used. The effects of temperature, reaction times and use of catalysts were correlated with the distribution of gas, liquid and residues yield

\subsection{Mass balance analysis}

The mass balance was determined after the reaction by weighing the raw material and the products using an analytical balance model G R-200 with an accuracy of 0.1 mg. This was done using equation 1 :

$$
\text { Input }_{(\mathrm{x} g)}=\text { Crude oil }_{(\mathrm{g})}+\text { Char }_{(\mathrm{g})}+\text { Gas }_{(\mathrm{g})} \ldots \ldots \ldots \ldots
$$

The mass of the gas was obtained by mass differences.

\subsection{Fractional distillation of crude oil}

Upgrading of the crude oil was done through fractional distillation. $\mathrm{x}$ mL aliquots of the crude oil was transferred

into a $1 \mathrm{~L}$ round bottomed flask connected to a rotary evaporator model R- 200 fractionating column. The system was heated within temperature range of 150 to $350{ }^{\circ} \mathrm{C}$. Petrol and diesel were recovered in separate volumetric flasks at temperatures of $150{ }^{\circ} \mathrm{C}$ and $350{ }^{\circ} \mathrm{C}$ respectively.

\subsection{Cost benefit analysis}

Cost benefit analysis was conducted through comparison of the monetary value in energy input and output. The energy input was calculated as total energy used during pyrolysis and fractionation as indicated in equation 2 to 4 . An assumption was made that all input energy was consumed and that there were no energy losses.

The Input (energy) used by the reactor for pyrolysis of $500 \mathrm{~g}$ HDPE and during Fractional distillation:

Input energy: Reactor $(2 \mathrm{kWh} \times 0.15 \mathrm{USD} / \mathrm{kWh})+$ Fractional distiller $(1 \mathrm{kWh} \times 0.15 \mathrm{USD} / \mathrm{kWh})=0.45 \mathrm{USD}$

Output energy: Petrol $(6 \% \times 1.01$ USD $)+$ Diesel $_{(72 \% \times 0.90 \text { USD })}=$ 0.69 USD

Difference: Output energy (0.69 USD) - Input energy (0.45 USD) $=$ $0.24 \mathrm{USD}+\mathrm{Z}_{\mathrm{Nm}}{ }^{3} / \mathrm{USD}$ (Fuel gas) .......... (4)

\subsection{Energy Consumption}

Energy consumption for pyrolysis of HDPE was conducted according to equation 5 to 8 .

Energy input $=$ Energy output

\section{Energy equivalents: $1 \mathrm{kWh}=3.6 \mathrm{MJ}$}

Energy input: Reactor (reactor $2 \mathrm{kWh} \times 3.6 \mathrm{MJ}+$ fractional distiller $1 \mathrm{kWh} \times 3.6$ $\mathrm{MJ})=$ Electricity consumption $(10.8 \mathrm{MJ})$

Energy output: Petrol $\left(0.2949 \mathrm{~m}^{3}\right) \times$ calorific value $(41.92$ $\left.\mathrm{MJ} / \mathrm{m}^{3}\right)+$ Diesel $\left(0.35964 \mathrm{~m}^{3}\right) \times$ calorific value $\left(46.10 \mathrm{MJ} / \mathrm{m}^{3}\right)$ $=204.96 \mathrm{MJ}$

Energy consumption: Energy input (10.8 MJ) / Energy output $(204.96 \mathrm{MJ})=5.27 \%+\mathrm{Z} \mathrm{MJ} / \mathrm{Nm}^{3}$ (fuel gas).

\section{Results and Discussion}

\subsection{Pyrolysis products from HDPE, LDPE and PP}

Crude oil and solid residue (char) obtained from the pyrolytic reactor are as shown in Figure 2 a, 2 b and 2 c.

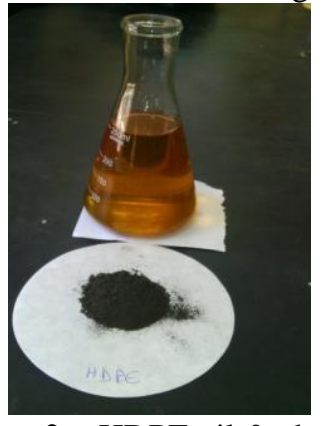

Figure 2a: HDPE oil \& char

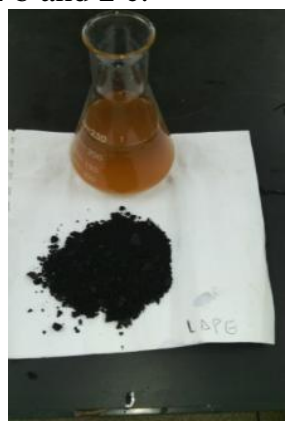

Figure 2b: LDPE oil \& char

\section{Volume 5 Issue 3, March 2016}




\section{International Journal of Science and Research (IJSR) \\ ISSN (Online): 2319-7064}

Index Copernicus Value (2013): 6.14 | Impact Factor (2014): 5.611

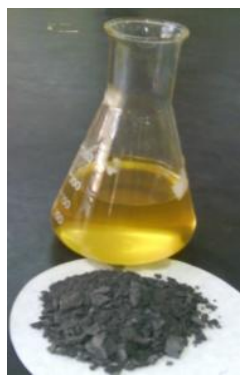

Figure 2c: PP oil \& char

Over $90 \%$ conversions of plastics to fuel hydrocarbons of gas and oil were achieved.

\subsection{Effect of temperature on product distribution}

Table 1 shows the percentage distribution results for pyrolysis products obtained at various temperature ranges. Diesel yield decreased with temperature rise, petrol and gas increased, while char and wax remained relatively constant

Table 1: Effect of temperature on product distribution

\begin{tabular}{|c|c|c|c|c|}
\hline \multicolumn{2}{|r|}{ Parameters } & \multicolumn{3}{|c|}{$\begin{array}{l}\text { Percentage product distribution for } \\
\text { plastic pyrolysis }\end{array}$} \\
\hline & \multirow{2}{*}{$\begin{array}{l}\text { Reaction temperature } \\
\text { range }\left({ }^{\circ} \mathrm{C}\right)\end{array}$} & PP & LDPE & HDPE \\
\hline & & $\begin{array}{c}\begin{array}{l}\text { Yield \% } \\
(\mathrm{w} / \mathrm{w})\end{array}\end{array}$ & $\begin{array}{l}\text { Yield \% } \\
(\mathrm{w} / \mathrm{w})\end{array}$ & $\begin{array}{l}\text { Yield \% } \\
\text { (w/w) }\end{array}$ \\
\hline \multirow[t]{3}{*}{ Diesel } & $250-350$ & $60 \pm 1.15$ & $70 \pm 1.37$ & $72 \pm 1.96$ \\
\hline & & $55 \pm 0.59$ & $69 \pm 1.43$ & $68 \pm 1.30$ \\
\hline & $450-500$ & $54 \pm 1.45$ & $66 \pm 1.96$ & $67 \pm 1.45$ \\
\hline \multirow[t]{3}{*}{ Petrol } & & $6 \pm 0.63$ & $8 \pm 0.76$ & $6 \pm 0.53$ \\
\hline & 3 & $8.2 \pm 0.76$ & $8 \pm 0.42$ & $7 \pm 0.32$ \\
\hline & $450-500$ & $9 \pm 0.43$ & $9 \pm 0.25$ & $8 \pm 0.64$ \\
\hline \multirow[t]{3}{*}{ Gas } & & $32 \pm 0.39$ & $17 \pm 0.33$ & $21 \pm 0.14$ \\
\hline & $0-450$ & $34 \pm 54$ & $20 \pm 0.43$ & $22.8 \pm 0.36$ \\
\hline & $450-500$ & $35.4 \pm 21$ & $23.2 \pm 0.2$ & $23.3 \pm 0.22$ \\
\hline \multirow{3}{*}{$\begin{array}{l}\text { Solid } \\
\text { residue } \\
\text { (char) }\end{array}$} & & & $5 \pm 1.08$ & $1 \pm 0.52$ \\
\hline & & $2 \pm 0.52$ & $2 \pm 1.87$ & $1 \pm 0.73$ \\
\hline & $450-500$ & $1 \pm 0.48$ & $1 \pm 0.78$ & $1 \pm 0.43$ \\
\hline \multirow[t]{3}{*}{ wax } & $250-350$ & $1 \pm 0.83$ & $1.5 \pm 0.87$ & $1.4 \pm 1.23$ \\
\hline & & $0.8 \pm 0.67$ & $1 \pm 0.50$ & $1.2 \pm 1.32$ \\
\hline & $450-500$ & $0.6 \pm 0.58$ & $0.8 \pm 1.97$ & $0.7 \pm 0.98$ \\
\hline
\end{tabular}

\subsection{Effect of temperature rise to reaction time for HDPE}

As the temperatures increased, reaction time for HDPE decreased in the order $60 \pm 2.37>25 \pm 1.05>15 \pm 1.47$ minutes respectively as shown in Figure 3a, 3b and 3c.

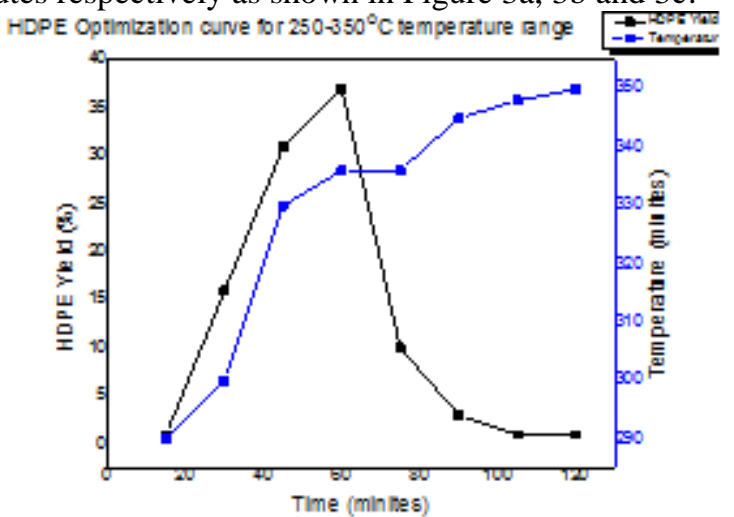

Figure 3a: optimization curve for HDPE at $200-350{ }^{\circ} \mathrm{C}$ temperature range

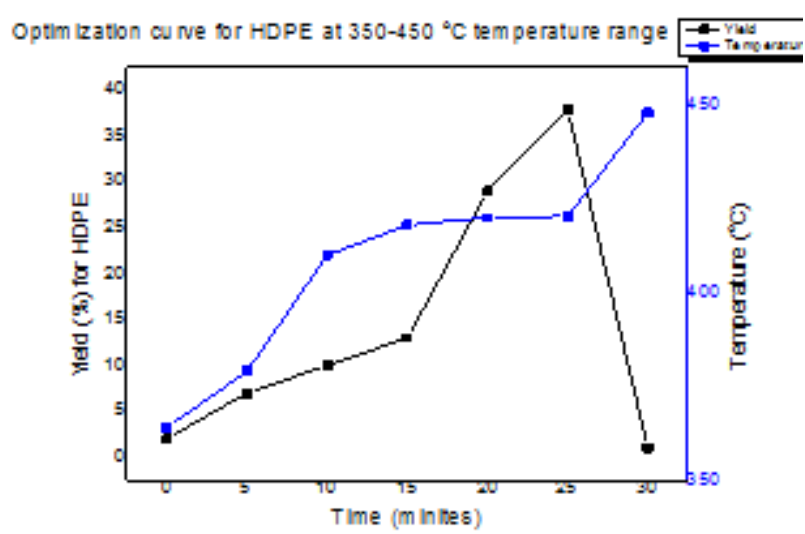

Figure 3b: optimization curve for HDPE at $350-450{ }^{\circ} \mathrm{C}$ temperature range

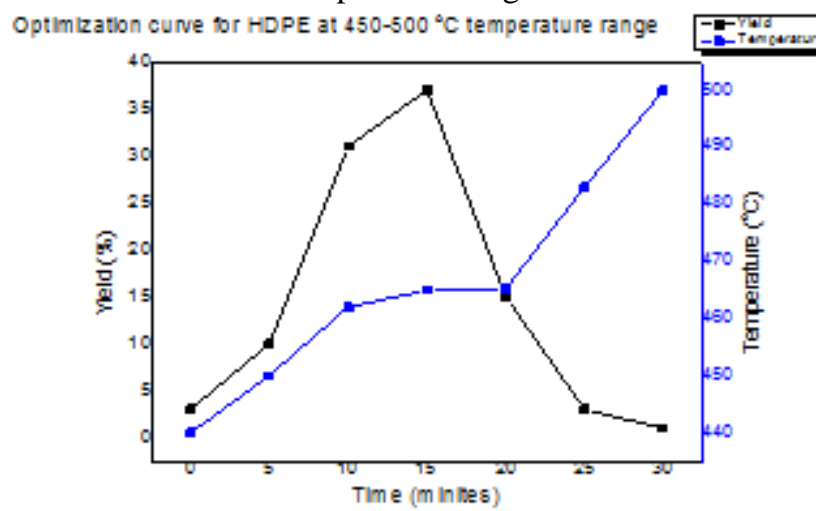

Figure 3c: optimization curve for HDPE at $450-500{ }^{\circ} \mathrm{C}$ temperature range

\subsection{Effect of increased heating rates to products distribution}

Diesel yield decreased with increased heating rates, petrol and gas yield increased, char and wax yield remained relatively constant. These results can be observed in table 2.

Table 2: Effect of heating rates to product distribution

\begin{tabular}{|c|c|c|c|c|}
\hline \multirow[t]{3}{*}{ Parameter } & \multicolumn{4}{|c|}{$\begin{array}{l}\text { Percentage product distribution for plastic } \\
\text { pyrolysis for } 200-350{ }^{\circ} \mathrm{C} \text { temperature range }\end{array}$} \\
\hline & \multirow[b]{2}{*}{ Heating rate } & $\mathrm{PP}$ & LDPE & HDPE \\
\hline & & $\begin{array}{l}\text { Yield \% } \\
(\mathrm{w} / \mathrm{w})\end{array}$ & $\begin{array}{l}\text { Yield \% } \\
(\mathrm{w} / \mathrm{w})\end{array}$ & $\begin{array}{l}\text { Yield \% } \\
(w / w)\end{array}$ \\
\hline \multirow{3}{*}{ Diesel } & $5^{\circ} \mathrm{C} / \mathrm{min}$ & $60 \pm 1.67$ & $70 \pm 1.32$ & $72 \pm 1.50$ \\
\hline & $10^{\circ} \mathrm{C} / \mathrm{min}$ & $58 \pm 0.54$ & $65.6 \pm 1.26$ & $66 \pm 1.78$ \\
\hline & $15^{\circ} \mathrm{C} / \mathrm{min}$ & $53 \pm 0.69$ & $62.3 \pm 0.45$ & $62.6 \pm 1.4$ \\
\hline \multirow{3}{*}{ Petrol } & $5^{\circ} \mathrm{C} / \mathrm{min}$ & $6 \pm 0.54$ & $8.3 \pm 0.37$ & $6 \pm 0.46$ \\
\hline & $10^{\circ} \mathrm{C} / \mathrm{min}$ & $7 \pm 0.23$ & $7.6 \pm 0.14$ & $5 \pm 0.67$ \\
\hline & $15^{\circ} \mathrm{C} / \mathrm{min}$ & $8 \pm 0.31$ & $6.2 \pm 0.31$ & $4 \pm 0.72$ \\
\hline \multirow{3}{*}{ Gas } & $5^{\circ} \mathrm{C} / \mathrm{min}$ & $31 \pm 1.04$ & $15.77 \pm 1.46$ & $20 \pm 1.08$ \\
\hline & $10^{\circ} \mathrm{C} / \mathrm{min}$ & $33.4 \pm 1.3$ & $22.97 \pm 1.21$ & $26.7 \pm 1.9$ \\
\hline & $15^{\circ} \mathrm{C} / \mathrm{min}$ & $34.7 \pm 1.6$ & $34.2 \pm 0.43$ & $32.2 \pm 2.7$ \\
\hline \multirow{3}{*}{$\begin{array}{l}\text { Solid } \\
\text { residue } \\
\text { (char) }\end{array}$} & $5^{\circ} \mathrm{C} / \mathrm{min}$ & $2 \pm 0.57$ & $5 \pm 1.21$ & $1 \pm 0.67$ \\
\hline & $10^{\circ} \mathrm{C} / \mathrm{min}$ & $1 \pm 0.5$ & $3 \pm 0.54$ & $1 \pm 0.67$ \\
\hline & $15^{\circ} \mathrm{C} / \mathrm{min}$ & $1 \pm 0.72$ & $1 \pm 0.37$ & $1 \pm 0.43$ \\
\hline \multirow{3}{*}{ wax } & $5^{\circ} \mathrm{C} / \mathrm{min}$ & $1 \pm 0.32$ & $1.03 \pm 0.42$ & $1.0 \pm 0.27$ \\
\hline & $10^{\circ} \mathrm{C} / \mathrm{min}$ & $0.6 \pm 0.34$ & $0.95 \pm 0.65$ & $1.3 \pm 1.05$ \\
\hline & $15^{\circ} \mathrm{C} / \mathrm{min}$ & $0.8 \pm 0.57$ & $0.6 \pm 0.50$ & $0.8 \pm 0.17$ \\
\hline
\end{tabular}




\section{International Journal of Science and Research (IJSR) \\ ISSN (Online): 2319-7064}

Index Copernicus Value (2013): 6.14 | Impact Factor (2014): 5.611

\subsection{Effect of catalyst on reaction time}

The Reaction times and cracking temperatures were lowered significantly with $\mathrm{t}$ calculated $>\mathrm{t}$ critical (One-way, paired t-test, $\mathrm{n}=0.05$ ) as shown in Figure 4 and 5.

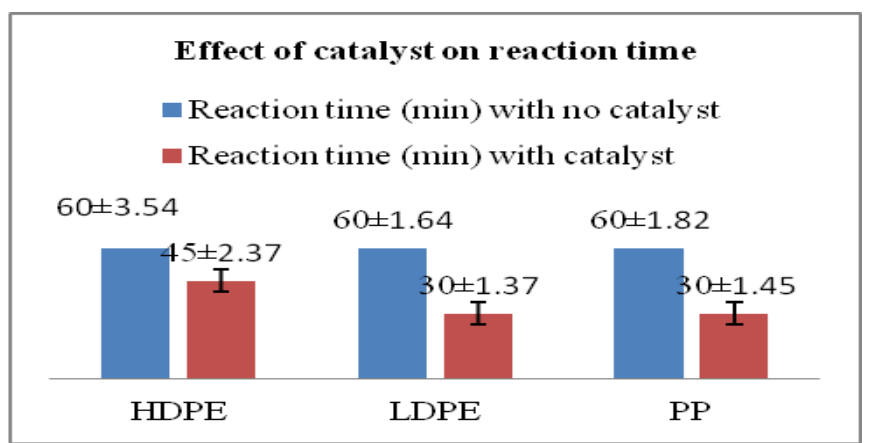

Figure 4: effect of catalyst on reaction time

Effect of catalyst on cracking temperatures $\backsim \mathrm{HDPE} \backsim \mathrm{LDPE} \approx \mathrm{PP}$

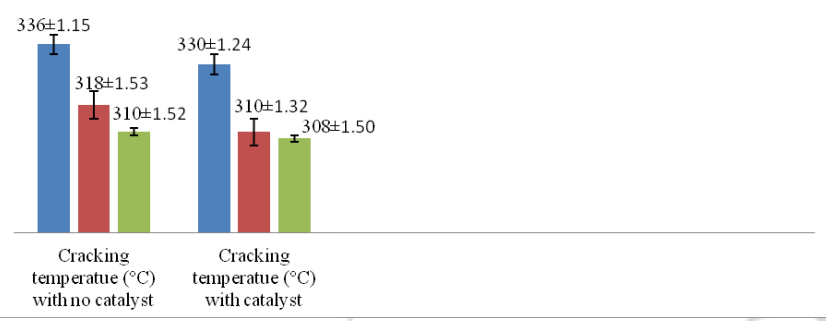

Figure 5: effect of catalyst on cracking temperatures

\section{Conclusion}

A rise in temperatures and heating rates resulted to shorter reaction times for the products in the reactor thus lowering the cost of production. As temperatures and heating rates increased, petrol and gas (light hydrocarbons) production increased significantly with ( $\mathrm{t}$ calculated $>\mathrm{t}$ critical), diesel yields decreased but not in significant amounts with ( $\mathrm{t}$ calculated $<\mathrm{t}$ critical) for one-way, paired t-test, $(n=0.05)$. These results agree with the findings confirmed by [11], [16]. The catalyst caused a significant increase in gas yield ( $\mathrm{t}$ calculated $>\mathrm{t}_{\text {critical }}$ one-way, paired t-test, $\mathrm{n}=0.05$ ) and a decrease in diesel yields. These results are similar to the observations and findings made by [17], [18]. Low heating rates of $5^{\circ} \mathrm{C} / \mathrm{min}$ and reaction temperature range of $350-450{ }^{\circ} \mathrm{C}$ provided best conditions for optimal production of diesel oils. These results agree with the findings made by [19]-[20]. The plant was found to be economically viable with less than 5\% energy of the total energy in $0.5 \mathrm{~kg}$ HDPE plastics getting consumed.

\section{Recommendation}

Pyrolysis (for energy recovery) provides a solution to waste plastics management problem in kenyan urban centers and rural set-ups. It presents an alternative means of obtaining cheap and affordable fuel to the local community. Pyrolysis technology is thus recommended as the best recycling approach for plastics.

\section{Acknowledgement}

The authors of this project are grateful to the JKUAT staff for technical assistance and to the Research, Production and Extensions (RPE-JKUAT) for funding the project.

\section{References}

[1] Nkwachukwu, O.I., et al., Focus on potential environmental issues on plastic world towards a sustainable plastic recycling in developing countries. International Journal of Industrial Chemistry, 2013. 4(1): p. 1-13.

[2] Qiao-fen, Y.A.N., Reuse of waste plastics. Environment Protection in Petrochemical Industry, 2000. 1(40-42).

[3] Bahri, G., Kenya., Sustainable Management of Plastic Bag Waste, 2005, IIIEE, Lund University: Lund, Sweden p. 29-30.

[4] Thompson, R.C., et al., Plastics, the environment and human health. current consensus and future trends. , 2009. 364(2153-2166).

[5] Thompson, R.C., et al., Plastics, the environment and human health:. current consensus and future trends.Phil. Trans. R. Soc. B, 2009. 364: p. 2153-2166.

[6] Barnes, D., et al., Accumulation and fragmentation of plastic debris in global environments. Phil. Trans. R. Soc B, 2009. 364.

[7] Gilpin R., W. D., and S. J., Production, distribution, and fate of polycholorinated dibenzo-p-dioxins, dibenzofurans, and related organohalogens in the environment. In Dioxins and health 2003. 2nd edn.

[8] Lithner, D., Å. Larsson, and G. Dave, Environmental and health hazard ranking and assessment of plastic polymers based on chemical composition. Science of the Total Environment 2011. 409: p. 3309-3324.

[9] Pikoń, K. and K. Gaska, Greenhouse gas emission mitigation relevant to changes in municipal solid waste management system. Journal of the Air \& Waste Management Association, 2010. 60(7): p. 782-788

[10] Bordynuik, J.W., Viable Production of Diesel From Non-Recyclable Waste Plastics, in Proceedings of the 21st Annual North American Waste-to-Energy Conference.2013, Florida, USA.

[11] Ademiluyi, F.T. and C. Akpan, Production of Fuel Oil from Pyrolysis of Waste Polyethylene (pure water sachets). Journal. Appl. Sci. Environ. Management, 2007. 11(3): p. 127-131

[12] Aguado, J., D.P. Serrano, and J.M. Escola, Fuels from waste plastics by thermal and catalytic processes: a review. Ind. Eng. Chem. Res, 2008. 47: p. 7982-7992.

[13] Onyango, D.O. and J.W. Kaluli, An Alternative Technology for Municipal Solid Waste Management Biomechanical and Environmental Engineering, 2014.

[14] Singhad, R., V. Tyagib, and T. Allen, An overview for exploring the possibilities of energy generation from municipal solid waste (MSW) in Indian. Renewable and Sustainable Energy Reviews, 2011. 15(9): p. 47974808.

[15] Eisa, M. and C. Visvanathan, Municipal solid waste management in Asia and Africa. A comparative analysis. Viena:UNIDO 2002. 
[16] Achilias, D.S., et al., Chemical recycling of plastic wastes made from polyethylene (LDPE and HDPE) and polypropylene $(P P)$. Journal of Hazardous Materials, 2007. 149(3): p. 536-542.

[17] Aguado, J., D. Serrano, and J. Escola, Catalytic Upgrading of PlasticWastes, in Feedstock Recycling and Pyrolysis of Waste Plastics. John Wiley \& Sons, Ltd: Mostoles, Spain, 2006: p. 73-110.

[18]Huang, W.C., et al., Thermochemical conversion of polymer wastes into hydrocarbonfuels over various fluidizing cracking catalysts. Fuel, 2010. 89(9): p. 23052316.

[19] Lee, C., et al., Effects of temperature distribution on the catalytic pyrolysis of polystyrene waste in a swirling fluidizedbed reactor. Catal. Today, 2003. 79-80: p. 453-464.

[20] Mlynková, B., E. Hájeková, and M. Bajus, Fuel Processing Technology. Chemical Papers 2008. 89: p. 1047- 1055 